\title{
Um curso de Teoria da Comunicação de Vilém Flusser: dimensão epistemológica e projeto pedagógico
}

\author{
Luis Mauro Sá Martino \\ Doutor; Faculdade Cásper Líbero, São Paulo, SP, Brasil \\ Imsamartino@gmail.com
}

\begin{abstract}
Resumo
Atividades de ensino nem sempre ganham a mesma importância de livros e artigos na produção de uma autora ou autor. No entanto, na medida em que as práticas pedagógicas têm uma dimensão epistemológica, cursos e programas de ensino podem mostrar aspectos menos conhecidos do pensamento de uma autora ou de um autor. Este artigo descreve algumas características de um curso inédito de Teoria da Comunicação ministrado por Vilém Flusser na Universidade de Marselha, em 1977. A partir de pesquisa documental, o curso foi analisado a partir de três questionamentos: o que é teoria da comunicação, quais são os conceitos agrupados sob esse nome e qual é seu lugar como disciplina em um curso universitário. Os resultados da pesquisa sugerem que, para Flusser, (a) Teoria da Comunicação é uma metadisciplina focada no estudo da interação humana, mediada ou não; (b) como tal, é ponto de passagem e confluência de outras disciplinas ou formas de conhecimento, e (c) o curso deve formar comunicólogos aptos, a partir desse conhecimento, a transformar as práticas de mídia e comunicação. Esses pontos são discutidos no contexto dos estudos contemporâneos de epistemologia da comunicação.
\end{abstract}

\section{Palavras-chave}

Vilém Flusser. Teoria da Comunicação. Epistemologia. Ensino.

\section{Introdução}

Em março de 1970, um memorando interno do professor Vilém Flusser, endereçado à Faculdade de Comunicação de Humanidades da Fundação Armando Álvares Penteado (FAAP), indicava o conteúdo das aulas dadas na disciplina Teoria da Comunicação. Esse 
documento, disponível para consulta digital no Arquivo Flusser, pode ser um ponto de partida para explorar alguns aspectos da atuação de Flusser como professor:

\author{
Faculdade de Comunicações e Humanidades da Fundação A. A. Penteado \\ Disciplina: Teoria da Comunicação \\ Matéria dada nas aulas em março de 1970 \\ Dia 03: Introdução \\ 10: Sinal, assinalado, símbolo, significado \\ 12: Símbolo, significado (cont.) \\ 17: Repertóio, Estrutura, Competência \\ 24: Feriado \\ 31: Memória, universo do discurso, código \\ NB: A matéria é idêntica no período matinal e noturno. \\ (FLUSSER, 1970, p. 1).
}

É muito raro um autor da importância de Vilém Flusser abrir espaço, em sua obra, para reflexões a respeito de sua prática pedagógica. Em Bodenlos, sua autobiografia filosófica, Flusser dedica cerca de trinta páginas às atividades de ensino na Fundação Armando Álvares Penteado, a FAAP, entre 1968 e 1972, e na Escola Politécnica da USP. Seus cursos são apresentados dentro de uma mirada epistemológica, com a atividade docente vista como tentativa, ou experimentação, de ideias e conceitos, parte integrante de suas atividades intelectuais.

Em geral, a atividade docente de uma autora ou de um autor é conhecida apenas a partir da publicação de cursos reunidos a partir de notas de aula de seus alunos. Nesses casos, é possível entrever não apenas aspectos da atividade docente, mas nuances do pensamento às vezes deixadas de fora do produto encaminhado para a publicação. Dentro da crescente produção sobre Flusser, como o livro organizado por Bernardo e Mendes (2000), Bernardo (2002), Baitello (2010) ou Batlickova (2010), os textos de Hanke (2004a, 2004b) destacam esse aspecto pedagógico e epistemológico.

A sala de aula, como lugar de interlocução, é também um lugar de elaboração do pensamento, "espaço de uma experiência”, lembra Lucrécia Ferrara (1993). O pedagógico inclui também uma dimensão epistemológica, ao menos na medida em que a escolha, pela professora ou pelo professor, dos saberes a serem levados para diálogo em sala de aula decorre de critérios relacionados às suas concepções a respeito de um tema ou uma ciência, como visto em outros momentos, como em Martino (2011, 2013, 2018). 
Poucas vezes, no entanto, essas reflexões são tornadas públicas pelo autor, como no caso de Flusser. Essa preocupação, destaca Bernardo (2007) no prefácio de Bodenlos, é “[...] relativamente inusitada para nós, acostumados que estamos ao desprestígio dos lugares de professor e mestre." (BERNARDO, 2007, p. 12). A atividade de Flusser como professor se estendeu por mais de trinta anos, do início dos anos 1960, no Brasil, e a partir de 1973, em várias universidades europeias, até seu falecimento.

Em sua autobiografia não há um programa detalhado de seu curso, mas as premissas e pressupostos epistemológicos trabalhados por ele na construção da disciplina. Além do livro, há depoimentos sobre sua maneira de agir em sala de aula, como o de Mendes (2000) ou as referências em Bernardo (2002), além de suas próprias considerações em Bodenlos. Isso levou à pergunta sobre as possibilidades de conhecer mais desse aspecto pedagógico da obra de Flusser, sobretudo a partir da importância que ele mesmo dá a esse trabalho: “[...] nosso trabalho se perdeu na sua maior parte" (FLUSSER, 2007, p. 275), não por alguma causa específica, mas porque "[...] todo trabalho acadêmico tende a perder-se na avalanche da superprodução generalizada." (FLUSSER, 2007, p. 275)

A consulta digital ao Arquivo Flusser de São Paulo ${ }^{1}$ foi o caminho para encontrar documentos que permitissem delinear essa dimensão do pensamento e da prática do autor. O material mais completo sobre o tema, no Arquivo, parece ser um programa de ensino e o material de aulas de um curso ministrado em 1977 na Universidade de Marselha-Luminy, onde foi professor visitante. Há cópias digitais do programa em francês e alemão, detalhando tópicos, objetivos e mesmo alguns procedimentos didáticos. São, no total, 53 páginas datilografadas, tamanho ofício, com os tópicos do programa de ensino, proposta de objetivos do curso e textos, escritos por Flusser, sobre as aulas. Não há indicações exatas da data das aulas ou do cronograma. Assim como em outras obras do autor, não há referências bibliográficas, apenas os temas e a proposta do curso.

Por uma questão de foco, este artigo se concentra na apresentação do programa de ensino de 1977, deixando para outro momento, por razões de espaço e limites, uma discussão do texto das aulas. 0 texto original, em francês, foi livremente traduzido aqui pelo autor.

Além disso, Informações contextuais foram obtidas nas indicações de Bodenlos e em outros materiais disponíveis no Arquivo, em particular quatro memorandos dirigidos à

\footnotetext{
10 acesso ao Arquivo Flusser é feito digitalmente, mediante cadastro, após solicitação aos organizadores - a quem agradeço a gentileza da permissão para consulta aos dados.
} 
FAAP indicando o conteúdo lecionado na disciplina. Trata-se, portanto, de um material heterogêneo, mas que permite discutir alguns aspectos dos cursos do ponto de vista de uma epistemologia da Comunicação.

Esse material foi analisado a partir de três questionamentos: o que é a Teoria da Comunicação? Qual o lugar dessa disciplina em um curso universitário? Quais são os saberes e conceitos agrupados sob esse nome?

No que se segue, o texto está dividido em três partes, nas quais se expõem, respectivamente: (1) o contexto de produção em Teoria da Comunicação nos momentos em que Flusser ministra seus cursos, e com os quais mantém um diálogo oblíquo; (2) os saberes reunidos nas unidades programáticas de seu curso de Marselha e a concepção de Teoria da Comunicação resultante desse agrupamento e (3) os objetivos do curso dentro de uma proposta ampla de formação de comunicólogos como pessoas aptas a intervir na realidade dos meios.

\section{0 contexto do ensino e pesquisa em Teoria da Comunicação}

O conceito de Teoria da Comunicação do momento em que Flusser ministra seus cursos é muito diferente da noção atual. Quem procurar um dos mais de vinte livros disponíveis intitulados Teoria da Comunicação, ou alguns dos programas de ensino da disciplina nas páginas de universidades, tende a encontrar uma divisão das teorias em escolas, organizadas de maneira mais menos cronológica, como sucessão de modelos ou paradigmas - como indicado em Martino (2018, 2019).

Essa divisão não existia na época dos cursos de Flusser - ela só começa a ser adotada nos livros a partir de 1993. Até então, a separação era por temas e núcleos de interesse. O programa de Flusser em Marselha segue essa divisão, apresentando um conjunto heterogêneo de assuntos, unidos sob uma concepção de comunicação como área do conhecimento que demandava elaborações teóricas próprias para ação prática.

Flusser usa o nome Teoria da Comunicação. Naquele momento, circulavam também as expressões "Teoria da Informação", como em Pignatari (1967), e "Fundamentos Científicos da Comunicação", em Sá (1971). Essas expressões eram usadas às vezes como sinônimos, e seus limites específicos frequentemente se sobrepunham. Em Bodenlos, Flusser (2007) afirma que o curso na FAAP lhe foi "imposto", mas em correspondência com a FAAP, ele recomenda essa denominação para a disciplina (FLUSSER, 2007, p. 272). Esse nome é 
mantido nas duas versões do curso da Universidade de Marselha (Théorie de la Communication e Kommunikation-Theorie), e também nos livros $O$ mundo codificado e Comunicologia.

Na FAAP, o curso de Teoria da Comunicação é ministrado num momento em que os contornos do ensino universitário de Comunicação parecem viver uma complexa indefinição. A título de exemplo, no início dos anos 1970, Dória (1972) registrava críticas de alunos em relação à generalidade dos cursos de Comunicação, à mistura de disciplinas lecionadas; mais de uma década depois, Venício lima (1983) fala de uma "crise de identidade" da Comunicação, em particular de seu referencial teórico.

Qual era esse referencial? A bibliografia da área, no caso brasileiro, era composta sobretudo de livros estrangeiros, embora os primeiros trabalhos brasileiros, como Informação. Linguagem. Comunicação, de Décio Pignatari (1967), e Teoria Geral da Comunicação Coletiva, de Vellozo (1969) Sociologia da Comunicação, de Gabriel Cohn (1969), datem dessa época, assim como as coletâneas Teoria da Cultura de Massa, organizada por Luiz Costa Lima (1969), e Comunicação e Indústria Cultural, organizada por Gabriel Cohn (1971), ambas trazendo alguns dos textos do que se tornaria um cânone das teorias da comunicação.

Se a área coberta pela Teoria da Comunicação enfrenta problema de definição até hoje, seria possível dizer que, nesse primeiro momento de formação, as fronteiras epistemológicas da Comunicação estavam sendo esboçadas no conflito e na articulação com outras áreas do conhecimento. Essa produção inicial tratava de uma ampla gama de assuntos, da Biologia à Sociologia da Mídia, passando por questões de Estética, Semiótica e Literatura.

No circuito internacional, com o qual Flusser dialoga no momento do curso de Marselha, essa literatura teórica poderia ser dividida, em linhas bastante gerais, em duas vertentes principais, seguindo parcialmente Merton (1970) e Eco (1995).

A primeira é representada pelas preocupações com a informação, códigos e linguagens, a questão do sentido e sua circulação. Os referenciais são originários da Semiótica, da Linguística e da Teoria da Informação, buscando também pontos da Cibernética e recebendo o impacto da produção de Marshall McLuhan, então recémtraduzida no Brasil. Ao que parece, a noção dominante de "informação", às vezes aproximada da ideia de "signo" - sobretudo, por exemplo, nos trabalhos inicias de Umberto Eco $(2014,2009)$ como Obra aberta e A estrutura ausente -, prevalecia nessa vertente de 
estudos da Comunicação. Ressonâncias do estruturalismo, bem como as primerias indicações de suas fissuras e insuficiências, parecem orientar essa primeira perspectiva.

Uma segunda vertente, pautada na Filosofia e nas Ciências Sociais, se debruça sobre as relações entre os meios de comunicação e a sociedade, discutindo as condições de produção da mensagem e traçando seus desdobramentos em termos de efeitos. No momento em que Flusser ministra seu curso na FAAP, a bibliografia disponível no Brasil é formada por traduções dos livros dos norte-americanos Wilbur Schramm, Charles R. Wright e Charles Steinberg.

Flusser, nos cursos, dialoga parcialmente com ambas.

Se, no início, sua preocupação parece ser com as questões da técnica e dos códigos, há igualmente interesse em compreender esse cenário técnico e corporativo em termos de suas ligações e consequências para o humano. Essa intersecção acontece na medida em que Flusser (2007) entende a Teoria da Comunicação como disciplina localizada entre os estudos da técnica, de um lado, e o terreno das relações humanas, de outro. A disciplina, na visão de Flusser, parece ser elástica o suficiente para englobar em si tanto a discussão de códigos e técnicas quanto aos seus desdobramentos sociais.

Ao mesmo tempo, o autor procura ir além dessas perspectivas.

Jogando com as palavras, o curso de Teoria da Comunicação de Flusser parece explodir a concepção disciplinar, não no sentido de buscar uma interdisciplinaridade, mas pela visão da Comunicação como um espaço de passagem, responsável pela elaboração das condições fundamentais de compreensão das outras disciplinas, sejam técnicas ou humanísticas. Para utilizar a expressão de Signates (2017), quase uma "ciência básica tardia" a ser ministrada não como disciplina ordinária ao lado de outras, mas como base para pensar a realidade a partir das questões comunicacionais que emergem, e perpassam, o conjunto de outras práticas sociais. Em Bodenlos, Flusser (2007) apresenta uma relação desses saberes, a partir dos quais foi elaborado o Quadro 1:

Quadro 1 - Os campos de competência da Teoria da Comunicação

\begin{tabular}{|c|c|c|}
\hline Campo da competência & Objetos & Métodos indicados \\
\hline Nervos & $\begin{array}{c}\text { Comunicações auditivas, } \\
\text { visuais, táteis, olfáticas }\end{array}$ & Fisiologia, behaviorismo \\
\hline Função & $\begin{array}{c}\text { Comunicação de massa, de } \\
\text { elite, closed circuit, etc. }\end{array}$ & Sociologia, psicologia social \\
\hline Dinâmica & $\begin{array}{c}\text { Diálogo, discurso, rede, } \\
\text { irradiação, árvore, elipse }\end{array}$ & $\begin{array}{c}\text { Cibernética, teorias dos } \\
\text { jogos }\end{array}$ \\
\hline
\end{tabular}




\begin{tabular}{|c|c|c|}
\hline Símbolo & $\begin{array}{c}\text { Comunicações denotativas, } \\
\text { conotativas, imaginativas, } \\
\text { conceituais }\end{array}$ & Crítica literária; estética \\
\hline Informação & $\begin{array}{c}\text { Comunicações originais, } \\
\text { banais, kitsch }\end{array}$ & Teoria da informação \\
\hline Mensagem & $\begin{array}{c}\text { Comunicações imperativas, } \\
\text { indicativas, exclamatórias, } \\
\text { inquisitórias }\end{array}$ & Análise lógica \\
\hline Canais & $\begin{array}{c}\text { Comunicações } \\
\text { unidimensionais, } \\
\text { multidimensionais, } \\
\text { diacrônicas, sincrônicas }\end{array}$ & Psicologia da Gestalt \\
\hline Social & $\begin{array}{c}\text { Comunicações de trabalho, } \\
\text { de consumo, de diversão }\end{array}$ & Economia, sociologia \\
\hline
\end{tabular}

Fonte: Adaptado de Flusser (2007, p. 272).

Nem em Bodenlos, nem no programa do curso de Marselha ou em sua correspondência sobre as suas práticas docentes há referências aos livros em circulação em sua época, e menos ainda ao que se poderia chamar de estudos de comunicação. Como não há, em nenhum momento, indicação de bibliografia, não é possível saber exatamente com quem Flusser estabelece conexões. A julgar pelos depoimentos esparsos de seus alunos, bem como pela gama variada de temas abordados, Teoria da Comunicação, para ele, dialoga mais com a Filosofia do que com outros estudos da área.

Não somente os interlocutores que Flusser escolhe vêm de outras áreas, mas seu curso dedica pouco espaço ao estudo da Sociologia da Mídia no sentido mais estrito do termo - e que era objeto de estudos de toda uma Sociologia dos Meios de Comunicação desenvolvida nos Estados Unidos. Apenas a título de comparação, o curso de Teoria da Comunicação ministrado na mesma época por Nelly Novaes Coelho (1970), na Escola de Comunicações e Artes da Universidade de São Paulo, dialoga sobretudo com os estudos norte-americanos e europeus de Comunicação, destacando, de um lado, a então chamada “comunicação de massa" e, por outro, alguns elementos dos estudos da linguagem como interação pessoal (MARTINO, 2019).

0 curso de Flusser, ao menos na FAAP, pode ser situado em um momento inicial de várias definições - algumas delas, aliás, em discussão até hoje - do foco e da abrangência de um curso de Comunicação, as disciplinas que o compõem e, dentre elas, qual o lugar e o escopo de um curso de Teoria da Comunicação. A partir do exame do programa do curso da Universidade de Marselha, secundado pelas indicações referentes ao ensino na FAAP, é possível delinear algumas das propostas de Flusser relativas a essas questões. 


\section{0 programa de ensino: um percurso epistemológico}

É sintomático que as palavras "discurso" e "percurso", nota Orlandi (2005), compartilhem na raiz a ideia de "curso", do latim "cursus", próximo a "caminho" ou a "correr". Não seria de todo errado, nesse sentido, pensar um curso como uma trilha ou jornada, construída enquanto é percorrida, reelaborada conforme as características do trajeto. 0 curso de Teoria da Comunicação de Flusser se apresenta, ao mesmo tempo, como um discurso teórico e como percurso intelectual. Vale, portanto, um olhar mais próximo a partir do programa do curso de Marselha em 1977, secundado pela correspondência com a FAAP e as indicações em Bodenlos.

A proposta do curso vai além do plano dos conteúdos a serem lecionados. Flusser propõe uma divisão em três partes, indicadas com letras maiúsculas: "A: Curso de Teoria da Comunicação", "B: Formação de grupos intra-departamentais" e "C: Formação de grupos interdepartamentais" (FLUSSER, 1977) Embora não a mencione, Flusser parece retomar a ideia da Comunicação como Studium Generale: a proposta não é apenas de um curso, mas de uma reestruturação do lugar dos saberes das ciências humanas a partir da comunicação. Isso envolve a colaboração não apenas do seu, mas também de outros departamentos.

Como afirma Diogo Bornhausen (2015, p. 377): “[...] a proposta especial de Vilém Flusser para uma formação engajada consiste em ensinar comunicação através do ensino de teoria da comunicação". Dessa maneira, Flusser "[...] sugeriu um projeto educacional capaz de articular a integralidade do conhecimento e superar a separação entre ciência, política e arte." (BORNHAUSEN, 2015, p. 377).

0 item A, o programa de ensino, tem vinte tópicos e, por sua relevância, demanda citação integral a partir de Flusser (1977a):

Programa Pedagógico para o Departamento de Comunicação Visual e Áudio da Escola de Arte e Arquitetura

Marselha - Luminy

A: Curso de Teoria da Comunicação

(1) 0 processo da comunicação

(2) Informação e mensagem

(3) Os meios de comunicação

(4) Códigos, símbolos, significados

(5) Códigos tridimensionais, participação

(6) Códigos bidimensionais, imaginação

(7) Códigos unidimensionais, concepção 
(8) Diacronia e sincronia

(9) A revolução dos tecnoimaginária dos códigos

(10) As estruturas dialógicas da comunicação:

(a) mesas redondas (ciências, parlamentos, administrações)

(b) redes (filosofia, artes, mercados, PTT)

(11) A estrutura discursiva da comunicação:

(a) hierarquias (exércitos, burocracias, sistemas)

(b) teatrais (cinema, escolas, exposições, conferências)

(c) Anfiteatrais (meios de comunicação de massa, vitrinas, circos)

(12) Memória e decisão (cibernética e teoria dos jogos)

(13) Espaço público, espaço privado e política

(14) Mensagens informativas (o verdadeiro, o fictício, o falso)

(15) Mensagens imperativas (os modelos, as modas e as informações)

(16) Mensagens de experiência (arte de elite e de massa)

(17) A revolução técno-imaginária e a pedagogia

(18) A revolução técno-imaginária e a estrutura cultural

(19) A revolução técno-imaginária e a cidade

(20) A manipulação de códigos tecnológicos e de decodificação (FLUSSER, 1977a, p. 1).

O programa, com vinte tópicos e vários subitens, chama a atenção não apenas pela abrangência, mas também pela presença de temas caros ao universo dos estudos de Flusser. A preocupação inicial é com os códigos, nos itens 4 a 7 , focalizando seus tipos (tridimensionais, bidimensionais, unidimensionais). Eles são mencionados no programa em termos das formas de interação comunicacional (participação, imaginação, concepção). Note-se a ausência do conceito de código nulodimensional, talvez ainda não totalmente desenvolvida nesse momento. Como destaca Hanke (2004b),

A ciência da comunicação humana foi a área de conhecimento e o campo importante de ensino e pesquisa de Flusser ainda no Brasil, mas somente em sua fase européia o pensamento flusseriano, desenvolvido entre 1967 e 1972 no país, ganhou forma de publicação. (HANKE, 2004b, p. 64).

Outro ponto relacionado aos temas recorrentes de Flusser é a divisão entre estruturas dialógicas da comunicação e estruturas discursivas da comunicação, nos itens 10 e 11, já com os exemplos de cada uma - talvez indício das preocupações didáticas, no sentido de encontrar exemplos ou ilustrações dos conceitos a serem apresentados em aula.

A presença isolada de uma menção à política no item 13 chama a atenção por não encontrar um desnevolvimento maior, ao menos com esses termos, em toda a sequência da proposta de ensino. Isso não significa ausência de preocupações nesse sentido. A dimensão 
política se manifesta nos itens 14 a 16 no exame dos tipos de informação referentes às diversas práticas sociais: o problema da veracidade da informação e o caráter imperativo ou estético das mensagens em circulação.

Nos últimos itens, vale destacar a presença do conceito de tecnoimaginário, apresentado como revolução. É possível ver aí um dos pontos centrais da concepção de Comunicação de Flusser tal como apresentada no programa de ensino: a articulação entre a técnica, (entendida como o aparelho-programa do qual os seres humanos se tornam funcionários), e a criação de imagens responsáveis por povoar o tecido das práticas sociais.

Talvez não seja de estranhar que um projeto desse tamanho extrapole não apenas as fronteiras disciplinares, mas também departamentais: disposta a pensar a pluralidade das práticas sociais e profissionais e dos saberes lá situados a partir da singularidade das relações de comunicação em um mundo mediado pela tecnologia, uma universidade precisa rever sua configuração institucional, e a proposta de Flusser caminha nesse sentido.

Os itens B e C do curso requerem uma colaboração entre outros setores da Universidade:

B: Formação de grupos intra-departamento:

(1) 0 código fotográfico e a fenomenologia

(2) 0 código da fita de vídeo e a intersubjetividade

(3) A busca por gestos do cotidiano (codificação fundamental)

(4) O código de tradução para o autor e os "meta-códigos", [sic] (por exemplo: tradução da fotografia em texto escrito e modelo tridimensional).

(5) 0 diálogo sobre a dominação do técno-imaginário

C: Formação de grupos interdepartamentais

(1) A cidade como anfiteatro, como árvore e como mercado [sic], (o complexo dialético entre discursos e diálogos)

(2) As contradições da casa (a superfície de projeção, o fenômeno como "visão em tela", o porte como instrumento de engajamento, a garagem como regra da política).

(3) Escolha a pergunta em questão (estrutura do teatro e tabelas de referência; conservação e distribuição da informação e do trabalho; explosão dos códigos de linha e análise).

(4) 0 conceito, imagem e o super-mercado, [sic] (a função da arte na época técno-imaginária).

(5) A festa, a história e a análise dos sistemas (os três locais da codificação e a "cultura de massa"). (FLUSSER, 1977a, p. 1).

Aparecem novamente temas caros ao universo de Flusser, como a questão do vídeo e da fotografia, nos itens B1 e B2, e o problema dos gestos no item B3, ausente dos outros 
tópicos do programa. A questão política também é destacada, agora no item B5, em relação à "dominação do técnoimaginário" (FLUSSER, 1977a, p.1), embora não seja especificada a partir de qual leitura isso será feito.

No item C, o projeto da Comunicação como centro para a leitura do contemporâneo encontra contornos mais amplos, ligados a outras práticas culturais, sociais e políticas: há aproximações da Comunicação com as artes, em particular o teatro, e mesmo ecos antropológicos no estudo das festas e dos modos de habitar.

Uma leitura talvez apressada poderia questionar a possibilidade de encontrar alguma coesão diante desse conjunto de assuntos que percorre, de certa maneira, parte da extensão das ciências humanas. Um olhar mais atento indica coerência entre o tamanho dessa proposta e a concepção de Flusser sobre o lugar da Comunicação e da Teoria da Comunicação.

Ao ressaltar a centralidade da comunicação, Flusser não parece seguir na linha de um midiacentrismo ou determinismo tecnológico. Sua importância não é por seu caráter de eixo, mas de passagem: trata-se de criar uma forma de olhar o mundo a partir das relações de comunicação, tal como articuladas nos diversos ambientes do corpo e da técnica, de sua articulação no tecnoimaginário e suas repercussões em outras dimensões das vivências humanas.

Se é possível arriscar uma síntese, o curso de Teoria da Comunicação de Flusser se apresenta como o acionamento de um repertório conceitual para a compreensão dos processos sociais a partir das relações de comunicação: uma Teoria da Comunicação não se confunde, a julgar pelo programa, com as Ciências Sociais. 0 diferencial, no entanto, não é o objeto, mas a compreensão da realidade a partir do olhar para os modos de relação entre os indivíduos.

O curso se apresenta como tronco central de saberes destinados a compreender o que poderia ser entendido como o fato ou fenômeno da comunicação, e também, talvez em primeiro lugar, como reflexão prática das condições de vida do mundo contemporâneo; do modo como está estruturado, é uma espécie de programa para a compreensão crítica de uma modernidade - e, talvez, de formas de vida - que se desenvolve radicalmente intermediada pela presença de um tecnoimaginário.

Flusser não apenas pensa a Teoria da Comunicação como disciplina específica de um curso de Comunicação, mas propõe ligações da disciplina intradepartamentais e interdepartamentais. Sua proposta não é de uma sequência de aulas, mas de um conjunto de 
práticas e vivências acadêmicas pensadas a partir da Teoria da Comunicação. Essa proposta de trabalho se mostra coerente com a concepção de Flusser da comunicação como ponto de passagem entre os diversos saberes e, ao mesmo tempo, se debruça sobre o aspecto comunicacional de cada prática ou atividade social.

Esse programa, em sua realização, demandava também alterações na maneira de ensiná-lo, assim como em seus objetivos, e Flusser deixa indicações a respeito, assunto da próxima seção.

\section{0 lugar da teoria e do curso de comunicação}

Para Flusser (2007), lecionar era uma maneira de mudar o mundo. Em Bodenlos, falando de suas atividades como professor, afirma tratar dos "[...] aspectos pelos quais procurei modificar o mundo." (FLUSSER, 2007, p. 265). A transformação tinha início no que buscava nas classes. Em suas palavras, “[...] embora as aulas tenham representado para mim o verdadeiro desafio, jamais perdi os receptores de vista. Jamais esqueci minha meta: provocar inquietação nos receptores."(FLUSSER, 2007, p. 269).

Ao que parece, essa preocupação era correspondida. 0 depoimento de um de seus alunos na FAAP, citado por Bernardo (2002), mostra as aulas de Flusser como algo muito distante do modelo tradicional, não pelo uso de qualquer tipo de aparato tecnológico ou técnicas de ensino, mas pelo encadeamento de ideias na investigação dos mais variados temas. Isso permite notar ao menos dois pontos.

Primeiro, embora o curso da FAAP anteceda em pelo menos seis anos o de Marselha, nota-se, pelo depoimento do aluno e pelas indicações de Bodenlos, que algumas preocupações já povoavam suas atividades de ensino, como a utilização de uma perspectiva comunicacional para a compreensão de diversos fenômenos e a questão dos códigos. Havia também, nesse primeiro tempo de ensino da Teoria da Comunicação, uma preocupação em definir o escopo da disciplina, de um lado, e a abrangência de seu campo de atuação prática, de outro. Esse foco era amplo, como indica o Quadro 2:

Quadro 2 - Os níveis de estudo da comunicação

\begin{tabular}{|c|c|c|c|}
\hline Nível & Ontológico & Epistemológico & $\begin{array}{c}\text { Noeticamente } \\
\text { engajado }\end{array}$ \\
\hline Atribuição & $\begin{array}{c}\text { Define a } \\
\text { competência da }\end{array}$ & $\begin{array}{c}\text { Procura seu método } \\
\text { de estudo }\end{array}$ & $\begin{array}{c}\text { Modificar a situação } \\
\text { das comunicações }\end{array}$ \\
\hline
\end{tabular}




\begin{tabular}{|c|c|c|c|}
\hline $\begin{array}{c}\text { Pergunta de } \\
\text { pesquisa }\end{array}$ & disciplina & Que é comunicação \\
humana? & $\begin{array}{c}\text { Como comunicações } \\
\text { humanas podem ser } \\
\text { investigadas? }\end{array}$ & $\begin{array}{c}\text { Como devem ser } \\
\text { comunicações } \\
\text { humanas e que } \\
\text { posso fazer nesse } \\
\text { sentido? }\end{array}$ \\
\hline
\end{tabular}

Fonte: Adaptado de Flusser (2007, p. 272).

Na apresentação do curso de Marselha, Flusser situa os estudos teóricos de comunicação na formação de comunicólogos que, dispondo do repertório conceitual para compreender os códigos, práticas e técnicas da comunicação, teriam condições de transformá-los. Se a sala de aula era o espaço de ação, a ideia de Flusser era amplificar a ressonância dessa mudança a partir das futuras atividades de suas alunas e de seus alunos. Referindo-se aos cursos da FAAP, Flusser (2007) indicava essa perspectiva:

Redefinindo, portanto: 'Que teoria da comunicação seja metadiscurso de todas as comunicações humanas de maneira que a estrutura de tais comunicações se torne evidente, a fim de poder modificá-la'. 'Comunicólogo' é quem dispõe de instrumentos para a modificação das comunicações humanas, e a teoria deve fornecê-los. Tal o programa da minha cadeira. (FLUSSER, 2007, p. 272).

É possível entender então que não existe, para Flusser, distinção entre teoria e prática na formação de comunicólogos: o conhecimento teórico é o meio de transformação prática. 0 curso também não busca formar técnicos para operação dos meios: o conhecimento teórico, como abstração, seria suficiente para as atividades do comunicólogo - não há, aliás, uma palavra sobre formação profissional no sentido atual, como preparação para um mercado de trabalho.

Um segundo ponto diz respeito ao formato. A sala de aula, espaço das práticas pedagógicas, também pode ser considerada, em alguma medida, o lugar de uma relação de comunicação. Flusser mostra também uma preocupação com a forma de ensinar. Esse interesse formal aparece em um de seus comentários em Bodenlos, no qual compara os códigos que usa:

Não sei distinguir claramente entre falar e escrever, entre ser professor e ser escritor como duas formas de engajamento. Falo como se estivesse escrevendo. A aula acadêmica em escolas brasileiras tem 50 minutos. Este é o espaço dentro do qual devia articular-me. (FLUSSER, 2007, p. 267). 
Flusser, pode-se entender, leva em consideração que o tempo da aula, assim como seu formato, não existem separados da realidade de suas alunas e de seus alunos, formados, já naquele momento, em um ambiente povoado pela mídia.

Em um texto do início dos anos 1970, Como filosofar em cultura de massa?, Flusser (1972a) coloca um problema relativo à prática docente: em linhas gerais, poderia ser resumido em como ensinar para alunas e alunos mergulhados no ambiente tecnoimaginário das mídias.

No texto, mais do que com o conteúdo, Flusser preocupa-se com a forma do ensino de filosofia e, em alguma medida, com a atividade filosófica. Os problemas do ensino de filosofia não estão primordialmente no conteúdo, mas na forma de apresentação e debate dos temas. 0 desafio, explica, é "[...] repensar os velhos problemas em termos radicalmente novos." (FLUSSER, 1972, p. 209). Por exemplo, diz o autor, apresentar questões filosóficas usando "artigos para jornal ou histórias em quadrinhos" (FLUSSER, 1972, p. 209).

Um curso não deixava também de ser um exercício de meta-reflexão sobre as possibilidades comunicacionais do ensino no ambiente midiático. Como lembra Marcondes Filho (2006), Flusser confere à comunicação “[...] o papel que antes era o da filosofia, fato esse que combina com sua declaração anterior, de que hoje só se pode filosofar com os meios de comunicação. [vista como parte de] [...] uma busca filosófica, existencial, de sentido." (MARCONDES FILHO, 2006, p. 429, grifo do autor).

A isso também se soma uma perspectiva histórica. Na apresentação do curso de 1977, Flusser situa a comunicação e, em particular, a Teoria da Comunicação dentro de uma perspectiva histórica que destaca o que ele chama de segunda revolução industrial. A primeira, explica Flusser (1977b), criou o proletário e o funcionário; a segunda provoca “[...] a reformulação da comunicação, isto é, da relação entre os seres humanos." (FLUSSER, 1977b, p. 1).

Aquilo que a tecnologia é para a primeira revolução, a comunicologia é para a segunda. As escolas técnicas, [sic] (incluindo as faculdade de medicina) são os centros de onde a vida na sociedade industrial é projetada. As escolas de comunicação estão em vias de se tornar esses centros na vida da sociedade pós-moderna. 0 técnico representa o artesanato e as ciências naturais aplicadas na sociedade industrial. 0 comunicólogo representa a arte e a ciência humana aplicada na sociedade pós-industrial. (FLUSSERb, 1977b, p. 1).

Mark Poster (2010) e Zhang (2019) creditam essa noção de crise e transformação às 
articulações do ser humano com a mídia, sobretudo em sua passagem da escrita para a imagem. Na síntese de Lucrécia Ferrara (2013), trata-se de “[...] uma transformação epistemológica que se dialetiza pela maneira como se desprograma e faz reconhecer a mudança que ocorre na passagem do plano e sua linearidade para a superfície que incorpora o espaço e seu volume." (FERRARA, 2013, p. 138).

Flusser (1977b), na apresentação do curso, indica que o crescimento das escolas de comunicação está ligado à demanda por profissionais aptos a lidar com o crescente aparato tecnoindustrial das corporações e das mídias, o que denomina "funcionários culturais".

Se não há ingenuidade em sua abordagem das escolas de comunicação, também não falta esperança na transformação a partir dos próprios meios, modificados pelo conhecimento do comunicólogo. Nas palavras de Menezes (2009), “[...] ele monta um cenário que nos leva do desalento à criação, do apocalipse às frestas de esperança, da dor que inibe ou paralisa até a dor que nos co(move) a agir apesar de tudo." (MENEZES, 2009, p. 176). Para Flusser, a pergunta é como os meios técnicos e os sistemas corporativos podem ser transformados de dentro, pelo conhecimento daqueles que os operam.

A resposta para essa pergunta pode ser encontrada na teoria da comunicação. A questão é, de fato, se existe, atualmente, a possibilidade de uma cultura que não seja massificante. Os milhares e milhares de jovens que se matriculam em escolas de comunicação têm dois motivos opostos. Por um lado, querem obter meios para poder participar do aparato cultural; por outro, querem usar os mesmos meios para desmascarar esse aparato e, certamente, evitar sua ditadura (FLUSSER, 1977c, p. 3).

Uma escola de comunicação, para Flusser, parece se apresentar como um espaço de construção de um conhecimento prático que, sem deixar de lado a formação operacional, deve ir além na formação não do funcionário cultural, mas de seu oposto complementar, o comunicólogo. De acordo com Hanke (2004b), para Flusser, a Teoria da Comunicação “[...] coloca no centro do processo o ser humano como animal simbolicum, o qual tem uma necessidade fundamental de se comunicar, e em seu entorno as mídias, que trabalham entre os homens e os objetos do mundo." (HANKE, 2004b, p. 61, grifo do autor).

Talvez não seja coincidência que esse tipo de preparação demande modalidades de ensino pensadas para ampliar a autonomia da produção de conhecimento por alunas e alunos, combinando as aulas, momento do discurso, com o espaço dialógico da interação entre estudantes na produção - e avaliação em grupo - de seus projetos. 
Flusser (1977a) explica isso no programa:

O objetivo do programa proposto aqui é duplo: (a) fornecer aos futuros comunicólogos uma base teórica e uma experiência prática da complexidade, do perigo e do desafio da situação comunicológica na qual estamos imersos e para conscientizá-los de sua responsabilidade em tal situação; e (b) transformar o Departamento de Comunicação em um espaço para comunicação dialógica entre os vários departamentos da Escola. As duas propostas estão implicadas: o departamento de comunicação como intermediário fornece uma visão concreta dos problemas de comunicação, e o estabelecimento de um intermediário impõe uma visão teórica da situação comunicológica. (FLUSSER, 1977a, p. 2).

A composição da disciplina Teoria da Comunicação, assim como seu lugar dentro do curso, derivam dessa concepção geral, mas não genérica, do que efetivamente pertence ao estudo da comunicação entendida como esse lugar de passagem.

\section{Considerações finais}

“Não seria melhor transmitir as dúvidas em vez dos modelos?", questiona Flusser (1972b) em um texto publicado em 22 de fevereiro de 1972 na Folha de S. Paulo, na coluna Posto Zero, que manteve durante esse ano. $\mathrm{O}$ autor se refere à necessidade de transformação das práticas docentes diante das transformações nas maneiras de pensar o ensino e seu conteúdo.

A atuação de Flusser como professor, vista a partir da análise de um programa de ensino, permite conhecer nuances de seu pensamento que se tornam mais visíveis no aspecto prático, por assim dizer, construído nas relações em sala de aula. O programa de Marselha, de 1977, assim como as indicações sobre os cursos lecionados na FAAP, permitem entrever um aspecto do panorama conceitual de Flusser também em termos didáticos e mesmo institucionais, na medida em que a proposta do curso, e o lugar da disciplina, são repensados no interior de uma nova organização dos saberes universitários em geral.

Um programa de ensino evidentemente oferece um panorama limitado para compreender o pensamento de uma autora ou de um autor, em particular quando existe, à disposição, uma obra publicada na qual temas e ideias podem ser estudados talvez com maior profundidade. 0 documento de Flusser é tomado muito mais como indício, no sentido 
dado a esse termo por Ginzburg (2009), do que como representação acabada de um pensamento. Mais ainda, é preciso levar em consideração que o programa estabelecido em um documento para encaminhamento à instituição não representa necessariamente o que foi lecionado em aula.

Apesar das limitações, trata-se de uma oportunidade de observar outros ângulos do pensamento de Flusser em ação, no modo como suas ideias são levadas à sala de aula, uma disciplinarização da epistemologia, para empregar um termo utilizado em outra ocasião - veja-se Martino (2013). Ou, como relembra Marczewska (2014), em outro contexto, uma observação dessa atividade de curadoria que comporta um aspecto didático-pedagógico, mas também epistemológico e poético.

0 curso é enfeixado em uma perspectiva de formação crítica de um comunicólogo preparado para compreender as modalidades possíveis de ação dos meios técnicos; a partir de seu conhecimento, a transformação. E, seguindo nessa dimensão de transformação, como indica Felinto (2018), “[...] o saber e a teoria passam a se constituir com o suporte da fantasia e do sonho. Trata-se, então, de projetar (entwerfen) mundos possíveis para o futuro. Pois a própria realidade, sustenta Flusser, começa a apresentar-se como fantasia." (FELINTO, 2018, p. 49, grifo do autor).

O curso propõe a centralidade da disciplina Teoria da Comunicação como maneira de formar uma mirada abrangente da realidade a partir de uma perspectiva comunicacional. A compreensão desse novo ambiente está reservada, no programa de Flusser, às comunicólogas e aos comunicólogos formados na intersecção de saberes abstratos com a operação de tecnologias materiais; comunicólogas e comunicólogos que, conhecendo as nuanças internas da formação do tecnoimaginário contemporâneo, podem encontrar novas maneiras de entendê-lo - e transformá-lo.

\section{Referências}

BAITELLO, Norval. A serpente, a maçã e o holograma. São Paulo: Paulus, 2010.

BATLICKOVA, Eva. Vilém Flusser no Brasil. São Paulo: Annablume, 2010.

BERNARDO, Gustavo; MENDES, Ricardo (org.). Vilém Flusser no Brasil. Rio de Janeiro: Relume Dumará, 2000.

BERNARDO, Gustavo. A dúvida de Flusser. Rio de Janeiro: Editora Globo, 2002. 
BERNARDO, Gustavo. Prefácio: A gente de Flusser. In: FLUSSER, Vilém. Bodenlos. São Paulo: Annablume, 2007, p. 7-16.

BORNHAUSEN, Diogo. Studium Generale. In: ZIELINSKI, Siegfried; WEIBEL, Peter; IRRGANG, Daniel (Orgs.) Flusseriana: an intellectual toolbox. Minnesota: Univocal Publishing, 2015, pp. 377-378.

COELHO, Nelly Novaes. Fundamentos Científicos da Comunicação II. Teoria da Comunicação. São Paulo: Escola de Comunicações e Artes da Universidade de São Paulo, 1970 (Série Comunicações).

COHN, Gabriel (org.). Comunicação e Indústria Cultural. São Paulo: Companhia Editora Nacional, 1971.

COHN, Gabriel. Sociologia da Comunicação. São Paulo: Pioneira, 1969.

ECO, Umberto. A estrutura ausente. São Paulo: Perspectiva, 2014.

ECO, Umberto. Apocalípticos e Integrados. São Paulo: Perspectiva, 1995.

ECO, Umberto. Obra aberta. São Paulo: Perspectiva, 2009.

FELINTO, Erick. Mare nostrum, mare alienum: identidade, epistemologia e a imaginação flusseriana dos fluxos. Matrizes, São Paulo, v. 12, n. 3, p. 45-58, 2018.

FERRARA, Lucrécia D'Aléssio. O conhecimento como dialética da imaginação. Matrizes, São Paulo, v. 7, n. 2, p. 131-142, 2013.

FERRARA, Lucrécia D'Aléssio. Sala de aula: espaço de uma experiência. Margem, São Paulo, v. 2, n. 1, p. 1-15, 1993.

FLUSSER, Vilém. Bodenlos. São Paulo: Annablume, 2007.

FLUSSER, Vilém. Como filosofar em Cultura de Massa? Revista Brasileira de Filosofia. Vol. 22, No. 86, 1972a, pp. 205-211.

FLUSSER, Vilém. Ensino Superior. Folha de S. Paulo, 22 de fevereiro de 1972b, p. 1. ESSAYS 8_PORTUGUESE-E. Arquivo Vilém Flusser São Paulo.

FLUSSER, Vilém. Memorando [Março 1970], p. 77. Cor_33-FACULDADE DE ARTES PLÁSTICAS DE COMUNICAÇÃO DA FUNDAÇÃO ARMANDO ALVARES PENTEADO [FAAP] AND OTHER FACULTIES OF THE UNIVERSITY OF SAO PAULO 1 OF 3. Arquivo Vilém Flusser São Paulo.

FLUSSER, Vilém. Programme pédagogique pour le department de la communication visuelle et audiovisuelle à l'École d'Art et d'Architeture Marseille-Luminy. [1977a]. COURSES 11_2-KTF [1900]_THEORIE DE LA COMMNUNICATION. Arquivo Vilém Flusser São Paulo. FLUSSER, Vilém. Le motif de mes cours à Luminy. [1977b]. COURSES 11_2-KTF [1900]_THEORIE DE LA COMMNUNICATION. Arquivo Vilém Flusser São Paulo. 
FLUSSER, Vilém. Theorie de la communication. [1977c]. COURSES 11_2-KTF [1900]_THEORIE DE LA COMMNUNICATION. Arquivo Vilém Flusser São Paulo. GINZBURG, Carlo. Mitos, emblemas, sinais. São Paulo: Companhia das Letras, 2009.

HANKE, Michael. A comunicologia segundo Vilém Flusser. Galáxia, São Paulo, v. 1, n. 7, p. 59-72, 2004b.

HANKE, Michael. Epistemologia na Teoria da Comunicação de Vilém Flusser. In: ENCONTRO ANUAL DA ASSOCIAÇÃO NACIONAL DOS PROGRAMAS DE PÓS-GRADUAÇÃO EM COMUNICAÇÃO, 13., 2004, São Bernardo do Campo. Anais [...]. São Bernardo do Campo: Universidade Metodista, 2004a. p. 1-14.

LIMA, Luiz C. (org.). Teoria da cultura de massa. Rio de Janeiro: Paz e Terra, 1969.

LIMA, Venício. Repensando as teorias da comunicação. In: MELO, José M. Teoria e pesquisa em comunicação. São Paulo: Intercom/Cortez, 1983, pp. 85-99.

MARCONDES FILHO, Ciro. A comunicação como uma caixa preta. Em Questão, Porto Alegre, v. 12, n. 2, p. 423-456, 2006.

MARCZEWSKA, Kaja. Modular form as curatorial practice. Journal of Writing in Creative Practice, Londres, v. 7, n. 1, p. 121-138, 2014.

MARTINO, Luís Mauro Sá. Uma apostila de Teoria da Comunicação de 1970. Revista Brasileira de História da Mídia, v. 8, no. 1, 2019, pp. 54-70.

MARTINO, Luís Mauro Sá. Genealogia dos Conceitos na Teoria da Comunicação: esboço de um panorama. Revista Alaic, v. 15, no.1, 2018, pp. 24-35.

MARTINO, Luís Mauro Sá. 0 que foi teoria da comunicação? Um estudo da bibliografia entre 1967-1986. Comunicação Midiática, v. 6, no.1, 2011, pp. 28-39.

MARTINO, Luís Mauro Sá. A disciplinarização da epistemologia na(s) Teoria(s) da Comunicação. InTexto, v. 29, no.1, 2013, p. 1-17.

MENDES, Ricardo. Pensando a fotografia (a memória). In: BERNARDO, Gustavo; MENDES, Ricardo (org.). Vilém Flusser no Brasil. Rio de Janeiro: Relume Dumará, 2000, pp. 193-221.

MENEZES, Eugenio. Comunicação, espaço e tempo. Comunicação, Mídia e Consumo, São Paulo, v. 6, n. 15, p. 165-182, 2009.

MERTON, Robert K. Sociologia: teoria e estrutura. São Paulo: Mestre Jou, 1970.

ORLANDI, Eni P. Análise de discurso. Campinas: Pontes, 2005.

PIGNATARI, Décio. Informação. Linguagem. Comunicação. São Paulo: Perspectiva, 1967.

POSTER, Mark. McLuhan and the cultural theory of media. Media Tropes Journal, [s. l.], v. 2, n. 2, p. 1-18, 2010. 
DÓRIA, Francisco Antonio. Escolas de Comunicação, Estagiários e a Empresa. Revista de Cultura Vozes, Ano 66, Vol. 66 no. 8, Outubro 1972.

SÁ, Adísia (org.). Fundamentos científicos da comunicação. Petrópolis: Vozes, 1971.

SIGNATES, L. A comunicação como ciência básica tardia. In: 25o. ENCONTRO DA ASSOCIAÇÃO NACIONAL DOS PROGRAMAS DE PÓS-GRADUAÇÃO EM COMUNICAÇÃO, 25, 2017, São Paulo. Anais [...] São Paulo: Compós, 2017, pp. 1-17.

VELLOZO, S. Teoria da Comunicação Coletiva. Rio de Janeiro: O Globo, 1969. ZHANG, Peter. Toward an interality-oriented philosophy of the digital. China Media Research, Zhejiang, v. 15, n. 4, p. 13-22, 2019.

\title{
A Communication Theory course by Vilém Flusser: epistemological dimensions and pedagogical project
}

\begin{abstract}
Teaching activities have not always been assigned the same importance as an author's published works. However, the courses taught by an author and their syllabuses may provide new insights into that author's ideas, as teaching is part of one's intellectual work and development. This paper outlines some characteristics of an unpublished Communication Theory course taught by Vilém Flusser at the University of Marseille, in 1977. Grounded on documentary research, it aims to understand what is communication theory, which are the concepts to which that label is applied and what is the place of communication theory in a university course. The main findings suggest that, to Flusser, (a) Communication Theory is a meta-discipline concerned with the study of human interaction, mediated or not; (b) it stands as a point of convergence between other fields of study and other forms of knowledge, and (c) it should train communication professionals that would be able to transform communication and media practices through that knowledge. These findings are discussed against the background of contemporary communication epistemology studies.
\end{abstract}

\section{Keywords}

Vilém Flusser. Communication Theory. Epistemology. Teaching.

Recebido em 25/02/2020

Aceito em 14/07/2020 